\title{
Spectral analysis of the support structure of the cylindrical container
}

\author{
Lubomir Prekop ${ }^{1, *}$ and Alzbeta Grmanova ${ }^{1}$ \\ ${ }^{1}$ Slovak Technical University in Bratislava, Faculty of Civil Engineering, Department of Structural \\ Mechanics, Radlinskeho 11, 81005 Bratislava, Slovak Republic
}

\begin{abstract}
The paper deals with dynamic analysis of a container. The analyzed structure consists of a steel support structure and a cylindrical container. The container is used for storage of road salt and other spreading materials during winter road maintenance. Three variants of support system of a structure have been analyzed. These have been introduced into the model as different boundary conditions. The spectral analysis was performed in which the response spectra taken from the Eurocode were used. In the final part, the results obtained from the seismic analysis of the structure (displacements and internal forces) have been presented.
\end{abstract}

\section{Introduction}

Structures for storage of various materials represent an important part of any manufacturing process. Material storage requires additional costs without increasing the value of the stored material. The basic requirement for storage tanks is to preserve the properties of stored materials and to prevent their deterioration.

The topic of this paper is modeling of three alternatives of bearing structures and their consecutive modal and spectral analysis. The characteristics of container, being designed by a specialized company, were used as input data, i.e.: its shape and dimensions, and specification of a stored material. Results have been presented in a form of a comparison of structural variants from various viewpoints.

\section{Structure of a cylindrical container}

The container is composed of a cylindrical silo with height $5.8 \mathrm{~m}$, a cone-shaped hopper with height $1.7 \mathrm{~m}$, an emptying hole with diameter $300 \mathrm{~mm}$, and a roof with height $1.5 \mathrm{~m}$. Overall container height including the hopper and the roof is $9.0 \mathrm{~m}$. The loading from the silo to the bearing structure has been transferred via 10 columns. A corrugated steel sheet with reinforcing elements forms the silo cladding [1-3].

\footnotetext{
* Corresponding author: lubomir.prekop@stuba.sk
} 

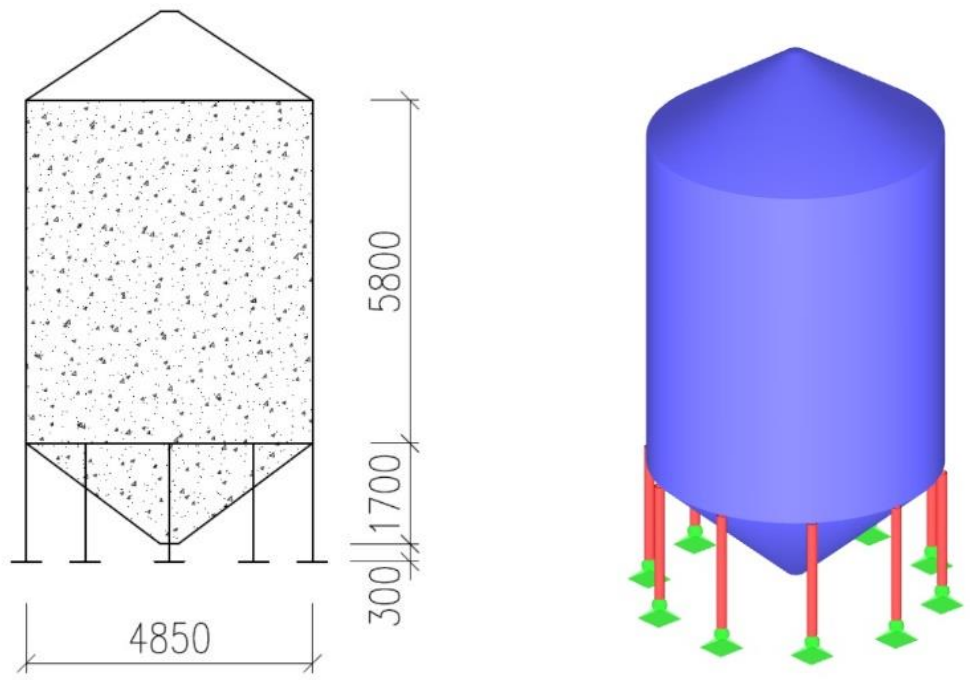

Fig. 1. Scheme of media size and volume in the cylindrical container.

\subsection{Model 1}

The first alternative of a container bearing structure consists of stiff beams interconnected by frames, and rods loaded by axial forces. Columns are made of steel rolled profiles HEB 360 and are hinged to the foundation structures. A transverse wall is of a HEA 360 profile. Stiffening elements have a circular cross-section RO 168x6.3. All structural elements are made of steel S235 [4].

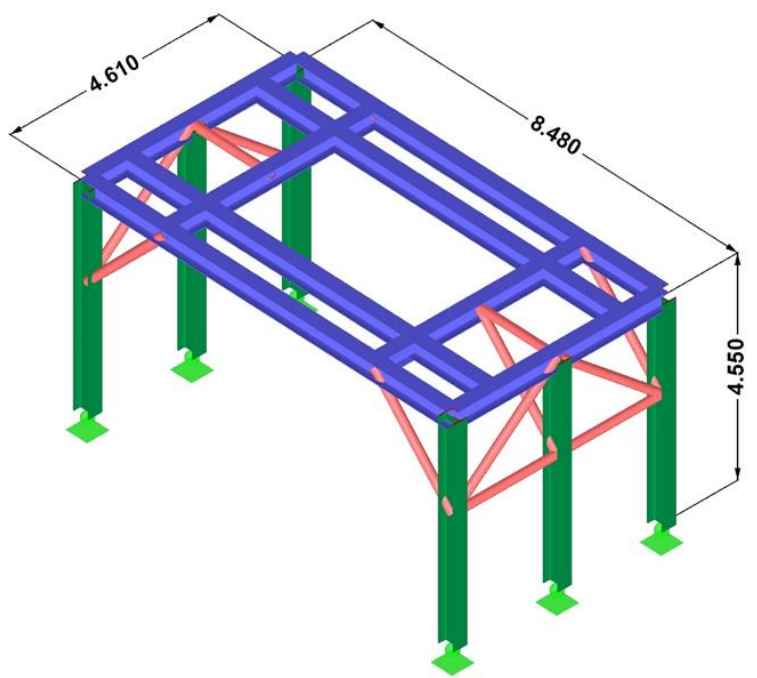

Fig. 2. Model 1.

\subsection{Model 2}

A second alternative is a combined structure, composed of a reinforced concrete wall $400 \mathrm{~mm}$ thick and of horizontal girders made from steel profiles HEA 450, hinged to the 
wall. The wall is clamped into the foundation structure. Structural elements have been manufactured from concrete C30/37 and steel S235 [4].

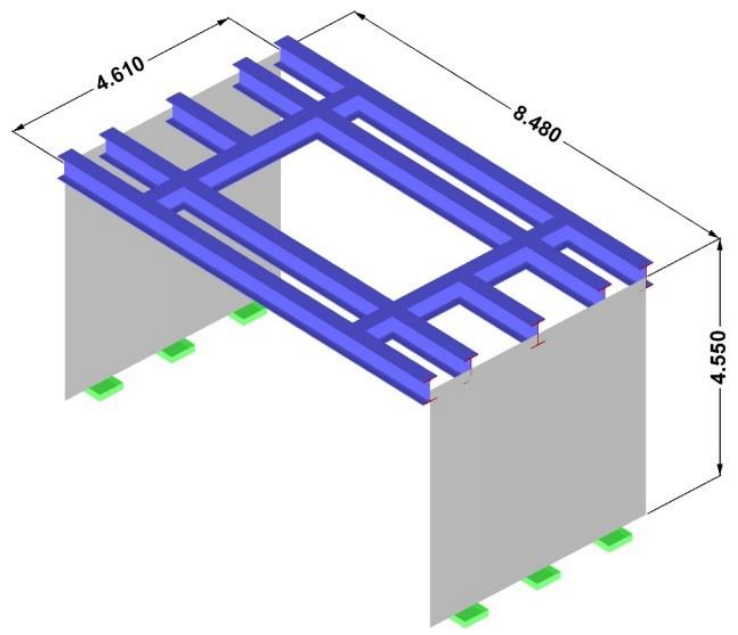

Fig. 3. Model 2.

\subsection{Model 3}

The third alternative of a container's bearing structure consists of columns and a lattice structure. Columns are composed of steel rolled profiles HEB 300 and they are hinged to the foundations. Upper stripe of a lattice structure is of a cross-section HEA 300. Diagonals, verticals and lower stripes are of a circular cross section RO 168x6.3. Columns and upper stripes of a lattice structure together create stiff frames to which the additional elements are hinged. The material used is steel S235 [4].

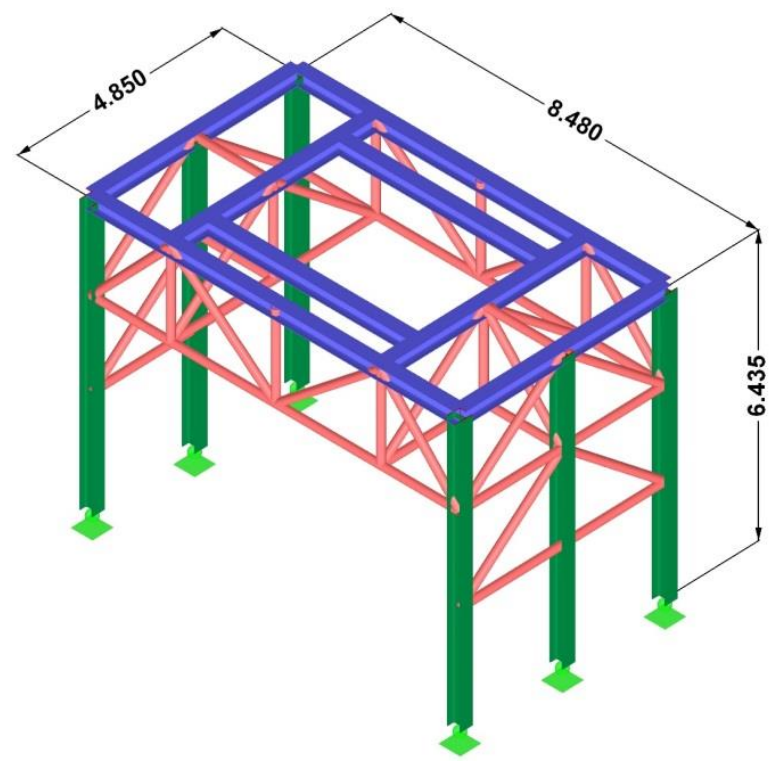

Fig. 4. Model 3. 


\section{Spectral analysis}

Spectral analysis of 3 models of the structure was performed using the add-on module of the RFEM program RF-DYNAM Pro [5], [6].

The RF-DYNAM Pro module is split into three parts:

1. The add-on module RF-DYNAM Pro - Natural Vibrations is the basic module that performs natural vibration analyses for member, surface and solid models.

2. A multi-modal and multi-point response spectra and time history analysis of the given structure can be performed with the module RF-DYNAM Pro - Forced Vibrations.

3. The add-on module RF-DYNAM Pro - Equivalent Loads offers the equivalent static force analysis (based on the multi-modal response spectra analysis) in accordance to various building standards.

RF-DYNAM Pro - Forced Vibrations is an extension of the RFEM add-on module RFDYNAM Pro - Natural Vibrations. Mechanical structures that are excited by transient or harmonic force-time or acceleration-time diagrams can be analysed using the modal analysis or the direct integration. Furthermore, multi-modal and multi-point response spectra analysis can be performed. The required spectra can be created according to the standards or user-defined. The add-on module contains an extensive library of accelerograms from earthquake zones. They can be used to generate response spectra.

The features of the response spectra analysis are listed below:

- Response spectra of numerous standards (EN 1998-1, DIN 4149, IBC 2012),

- Response spectra can be user-defined or generated from accelerograms,

- Direction-relative response spectra approach,

- Different response spectra can be assigned to different supports (multi-point option),

- Relevant mode shapes for the response spectra can be selected manually or automatically (the 5\% rule from EN1998-1 [1] can be applied),

- Calculation is performed within RF-DYNAM Pro and is therefore linear,

- Modifications of the stiffness matrix as defined in the Natural Vibration Cases are also used for the calculation of internal forces and deformations,

- Combination of the modal responses (SRSS rule or CQC rule) and combination of the results from different excitation directions (SRSS or 100\% / 30\% rule).

The results from the time history analysis are displayed in a time history diagram. Here, there is the possibility to superimpose different nodes or positions within one member. All results are displayed as a function of time. The numeric values can be exported to Excel. In case of a time history analysis, it is possible to export results of a single time step or filter the most unfavourable results of all time steps.

The response spectra analysis is based on the eigenvalues and mode shapes and also the internal forces, deformation and further results are calculated internally within RFDYNAM Pro, therefore the calculation is purely linear but the stiffness modifications as defined in the Natural Vibration Cases are used for the whole analysis. Only result combinations are exported. A combination of the modal responses and a combination of the results due to the components of the earthquake action are done internally.

The following graphs present the results of calculations in an explicit way. In the graph in Fig. 5 there is a comparison of structural deformations in the $x, y$, and $z$ axes directions for all structural models. The graph in Fig. 6 presents the comparison of values of internal forces (normal forces, transversal forces and bending moments) for all created structural models. 


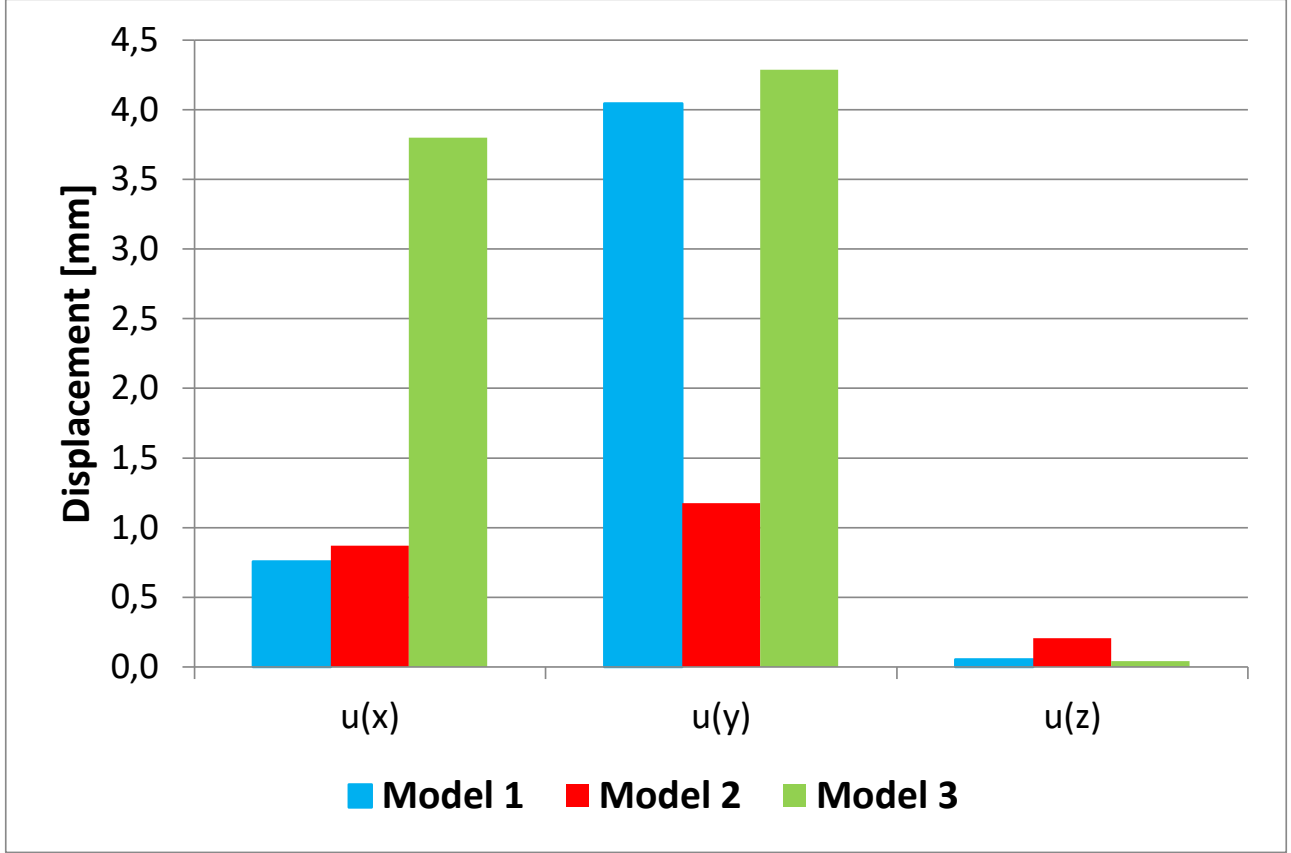

Fig. 5. Comparison of deformations in the directions of the coordinate axes for all models.

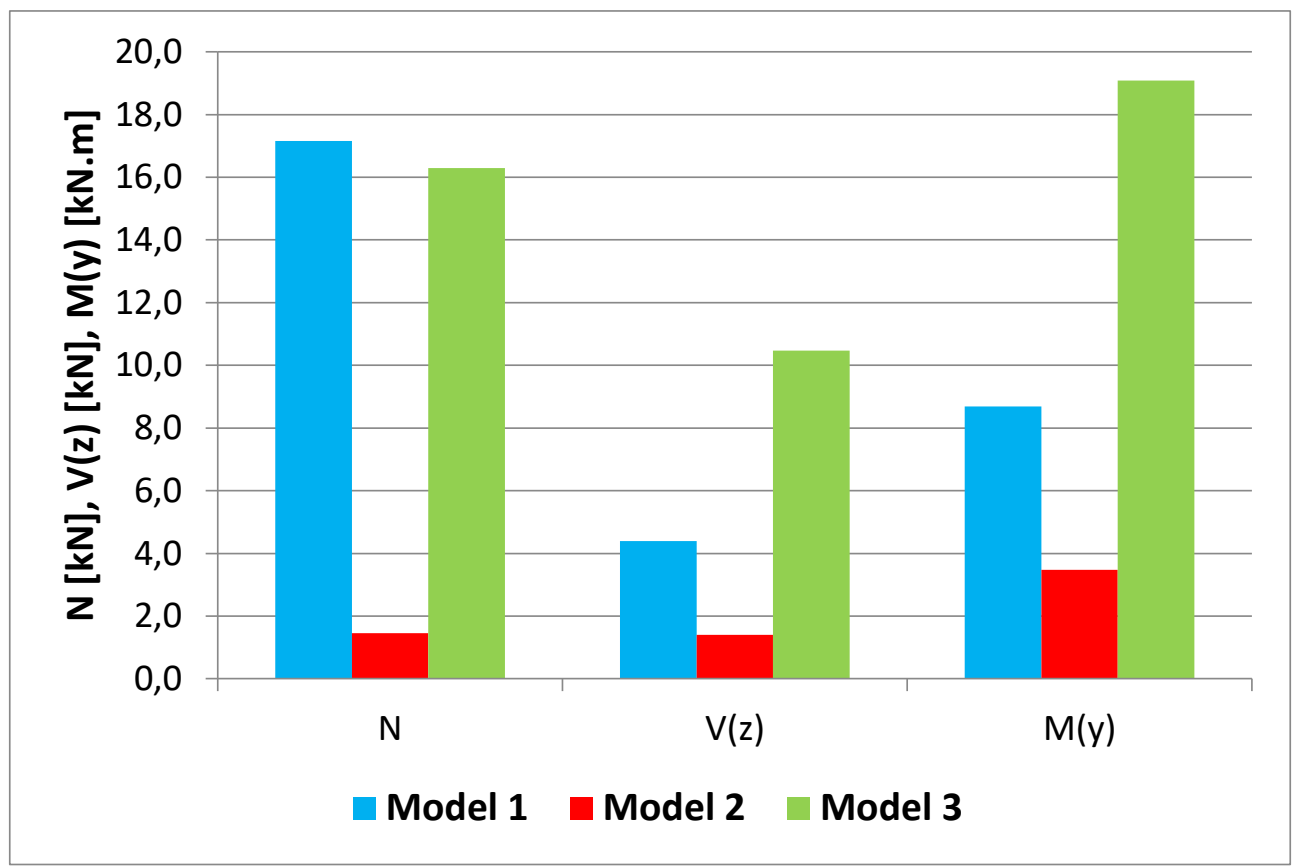

Fig. 6. Comparison of internal forces for all models. 


\section{Conclusion}

Presented results have been obtained considering the loading by seismic effects. They must be combined with loading by self-weight and by permanent load whereupon the extreme seismic combination can modeled. The results prepared in this way can serve for the design of the supporting structure. Based on the obtained results, it can be concluded that the most suitable model of the supporting structure in terms of deformations and internal forces is the model 2.

This paper was supported by Grant Agency VEGA, project No. 1/0412/18 and KEGA/025STU$4 / 2019$.

\section{References}

1. K. Kotrasová, E. Kormaníková, M. Vašina, Parametric study of seismic response of cylindrical tank, AIP Conference Proceedings, 2116, 120008 (2019)

2. K. Kotrasová, E. Kormaníková, Multiscale modeling of composite cylindrical tank, Data in Brief, 18, 1777-1783 (2018)

3. D. Kuchárová, J. Melcer, Identification of Some Dynamic Characteristics of a Bridge Structure, Procedia Engineering, 190, 304-309 (2017)

4. Manual RFEM 5, Dlubal Software s.r.o (2012)

5. Manual RF-DYNAM Pro, Natural Vibration Analysis, Response Spectra, Time History, Equivalent Static Forces, Program Description, Dlubal Software s.r.o (2016)

6. V. Salajka, P. Hradil, D. Frybort, M. Glockner, A comparison of spectral values obtained in bridge structures via radar interferometry and numerical calculations, MATEC Web of Conferences, 107, 00013 (2017)

7. STN EN 1993-1-1 (STN 73 1401) Eurocode 3: Design of steel structures, Section 1-1: General rules and rules for buildings 